\title{
SIMPLIFIED TECHNIQUE FOR CONSTITUTIVE ANALYSIS OF SFRC
}

\author{
Adas MESKENAS ${ }^{\mathrm{a}}$, Viktor GRIBNIAK $^{\mathrm{a}, \mathrm{b}}$, Gintaris KAKLAUSKAS ${ }^{\mathrm{a}}$, \\ Aleksandr K. ARNAUTOV ${ }^{\mathrm{b}}$, Arvydas RIMKUS ${ }^{\mathrm{a}}$ \\ ${ }^{a}$ Department of Bridges and Special Structures, Vilnius Gediminas Technical University, Saulètekio al. 11, \\ 10223 Vilnius, Lithuania \\ ${ }^{b}$ Institute of Polymer Mechanics (IMP), University of Latvia, Raina blvd. 19, 1586 Riga, Latvia
}

Received 03 Jan 2014; accepted 21 Mar 2014

\begin{abstract}
Steel fibre reinforced concrete (SFRC) has become widespread material in areas such as underground shotcrete structures and industrial floors. However, due to the absence of material models of SFRC reliable for numerical analysis, application fields of this material are still limited. Due to interaction of concrete with fibres, a cracked section is able to carry a significant portion of tensile stresses, called the residual stresses. In present practices, residual stresses used for strength, deflection and crack width analysis are quantified by means of standard tests. However, interpretation of these test results is based on approximation using empirically deduced relationships, adequacy of which might be insufficient for an advanced numerical analysis. Based on general principles of material mechanics, this paper proposes a methodology for determination of residual stress-crack opening relationships using experimental data of three-point bending tests. To verify the constitutive analysis results, a numerical modelling is utilised employing a nonlinear finite element analysis program ATENA. Simulated load-crack width relationships and moment-curvature diagrams were compared with the experimental data by validating adequacy of the derived constitutive models.
\end{abstract}

Keywords: steel fibre reinforced concrete, constitutive analysis, residual stresses, flexural members, crack width, deformations.

Reference to this paper should be made as follows: Meskenas, A.; Gribniak, V.; Kaklauskas, G.; Arnautov, A. K.; Rimkus, A. 2014. Simplified technique for constitutive analysis of SFRC, Journal of Civil Engineering and Management 20(3): 446-453. http://dx.doi.org/10.3846/13923730.2014.909882

\section{Introduction}

Steel fibre reinforced concrete (SFRC) is a cement based composite material reinforced with discrete randomly distributed fibres. A sufficient quantity of fibres (normally greater than $15 \mathrm{~kg} / \mathrm{m}^{3}$ ) added to the conventional concrete may have both technical and economic advantages, such as improved ductility, corrosion resistance and substantial reduction of laborious reinforcement work (Gribniak et al. 2013b). Despite its extensive and long-term use in specific areas, e.g. industrial floors and underground shotcrete structures, steel fibres have not occupied the general market of concrete structures. One of the main reasons is that the major design codes do not cover SFRC structures.

Quantification of the post-cracking strength of SFRC (provided by interaction between fibres and concrete) becomes a rather complicated issue due to diversity in the shape, material properties and bond characteristics of fibres (Gribniak et al. 2012). Post-cracking strength as the main parameter, describing behaviour of SFRC, appears because of its capability to sustain tensile stresses due to interaction between concrete and fibres crossing the crack plane. Tensile stresses, which appear in a crac- ked SFRC, are often referred as residual. For investigation of post cracking behaviour of SFRC, both direct and inverse techniques can be used. The direct analysis is dedicated to the prediction of SFRC response using the specified material models, whereas the inverse analysis aims at determination of the parameters of a material model employing the constitutive test results (Kaklauskas et al. 2011).

Generally, SFRC can be considered as a concrete with randomly dispersed fibres or as a homogeneous material - conventional concrete with improved material properties. In the first case, post-cracking response of the material is defined through meso-scale models (Lofgren 2005; Jones et al. 2008; Fuggini et al. 2013). At this research level, the bridging of the crack is based on the number of fibres across the crack plane and on concrete and fibre bond interaction properties during the crack opening. Involving a large number of generally stochastic parameters, such models tend to be very complex. Moreover, computational implementation of these models is time consuming. Therefore, the research carried out on the macro-scale and being associated to the inverse analysis is commonly proceeded analysing SFRC as a homogeneous material. Most of the models found in literature 
propose simple and continuous non-differentiable constitutive diagrams that are characterised through macroscopic material properties. These approaches focus either on residual stress-strain $\left(\sigma_{f r}-\varepsilon\right)$ (RILEM 2003; Dupont 2003) or on residual stress-crack opening width $\left(\sigma_{f r}-w\right)$ relationships (DBV 2001; RILEM 2002a; DafStb 2010).

Several test methods may be used to determine, directly or indirectly, residual strength of cracked SFRC. The axial tension test appears to be the most fundamental and straightforward method to define the fracture properties of a material, as the tensile stress-crack width $\left(\sigma_{f r}-w\right)$ relationship can be directly determined from the test results. However, the axial tension test is rather complicated to perform and it has been shown that the experimental results are affected by the test equipment and specimen interaction (RILEM 2001; Dupont 2003; Pujadas et al. 2013). Typically, bending tests of standard size (small in respect of full scale elements) beam specimens are the most currently used to characterize the postcracking response of SFRC. These can be based either on three-point bending tests on notched or un-notched specimens (RILEM 2003; CEN 2005) or on four-point bending tests (DBV 2001; CNR 2007). Based on these test results and the inverse analysis techniques, the tensile strength and the residual stresses are defined, which can be further used for the strength, deflection or crack width analysis of SFRC members (Dupont 2003; Slowik et al. 2006). It should be pointed out that a large scatter of the test results often accompanies the standard experiments on SFRC. It mainly depends on the number of fibres crossing the crack plane (Di Prisco et al. 2006; Gribniak et al. 2012).

Seeking to reduce the scatter of experimental results, an alternative and novel approach for obtaining residual stresses from beam tests was recently proposed by the authors (Gribniak et al. 2012, 2013c). Unlike the standard techniques based on tests of small bending specimens, the proposed approach uses data of momentcurvature diagrams obtained from flexural tests on full scale SFRC beams with bar reinforcement. Solving the inverse deformation problem, when the model parameters are selected in accordance to the given response of a real structure, an average stress-average strain relationship of SFRC in tension is derived. As it can be seen from the Figure 1, the obtained stresses for the SFRC members at a given strain consist of the stresses due to the tensionstiffening effect and the residual stresses due to fibre and concrete interaction. Thus, residual stresses can be quantified as the difference of stresses obtained for the SFRC and conventional RC elements. In this figure, $f_{c t}$ and $\varepsilon_{c r}$ are the reference tensile strength and cracking strain, respectively; $\sigma_{f r}$ is the residual tensile stress due to fibre interaction with concrete; $\sigma_{c t}$ and $\varepsilon_{c t}$ are the average stress and average strain of concrete in tension.

It can be pointed out that the fibre effect on tensionstiffening is related with two aspects: type and content of fibres and structural composition of the section. With the increasing area of bar reinforcement, relative influence of fibres to the stiffness of cracked element will decrease (Gribniak et al. 2012; Lee et al. 2013). With decreasing
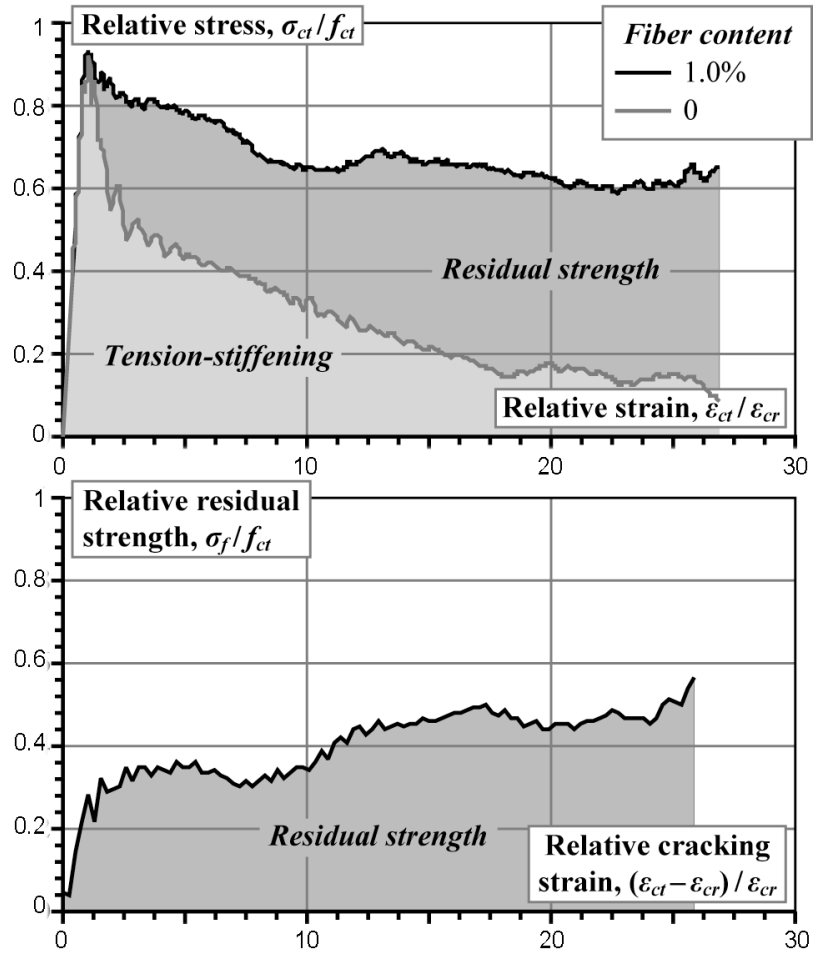

Fig. 1. Average stress-average strain response of tensile steel fibre reinforced concrete obtained from tests of beams with ordinary reinforcement bars (Gribniak et al. 2012)

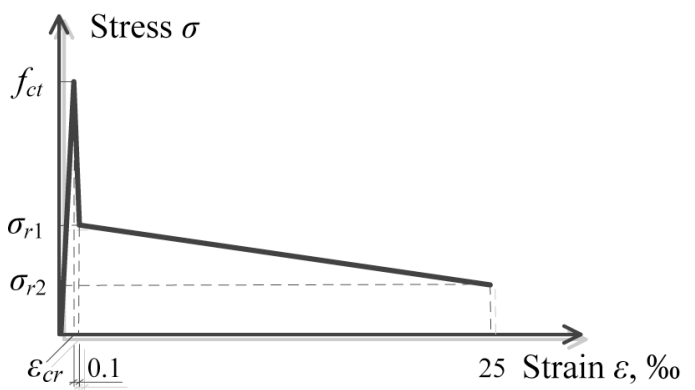

Fig. 2. Stress-strain relationship proposed in RILEM (2003)

cover of bar reinforcement, effectiveness of fibres might increase due to the restrained longitudinal crack opening. Application of micro-fibres can also give a positive effect on bond strength (Chao et al. 2009). In general, higher amount of fibres might increase the residual stresses; however, it can lead to higher possibility of structural defects (for instance, balling effect) and therefore reduce the bond strength. Holschemacher et al. (2010) and Ganesan et al. (2014) performed extensive investigation on this issue.

The current paper is dedicated to the determination of post-cracking behaviour of SFRC in tension. Seeking universality, the methodology for constitutive analysis of $\mathrm{SFRC}$ is proposed. The developed inverse technique determines residual stresses of SFRC in mechanically sound manner. Adequacy of the proposed technique was validated using experimental data of standard (small) and fullscale beams employing the derived residual strength models into nonlinear finite element analysis program ATENA as material law of SFRC in tension. 


\section{Constitutive modelling of SFRC}

One of the ways to define the post-cracking behaviour of SFRC was proposed by Naaman (2003). A simple analytical expression for residual strength was suggested accounting pull-out length ratio, the efficiency factor of fibre orientation in respect to the crack plane, and the group reduction factor associated with the number of fibres pulling out per unit area of the crack:

$$
f_{r}=\lambda_{1} \cdot \lambda_{2} \cdot \lambda_{3} \cdot \tau \cdot F ; \quad F=\frac{V_{f} \cdot l_{f}}{b_{f} \cdot \beta},
$$

where: $\lambda_{1}$ is the expected pull-out length ratio; $\lambda_{2}$ is the fibre orientation factor; $\lambda_{3}$ is the group reduction factor associated with the number of fibres pulling out per unit area; $\tau$ is the average bond stress of a single fibre embedded in the concrete; $V_{f}$ is the fibre volume percentage; $\beta$ is the bond factor, accordingly to Campione (2008), can be assumed being equal to 0.5 for round fibres, 0.75 - for crimped fibres, 1.0 - for hooked fibres; $l_{f}$ and $b_{f}$ are the length and the diameter of fibre, respectively. It is important to note that expression (1) gives constant value of the residual stresses being unacceptably rough for solving the advanced analysis problems.

Another method for assessing tensile behaviour of cracked SFRC was proposed in RILEM (2003). The method uses a tri-linear stress-strain relation of SFRC in tension and is derived from the experimental data of three-point bending test on the specimens with dimensions of $150 \times 150 \times 600 \mathrm{~mm}$. To control the cracking process, a notch at mid-span of the beam is formed that allows measuring the opening crack width. The postcracking response of SFRC is characterised by residual stresses $\sigma_{r 1}$ and $\sigma_{r 2}$ (Fig. 2), which correspond to experimental load values at different beam deformation stages at certain mid-span deflection (or crack width) values defined by the RILEM (2002b). The residual stresses are determined by following expressions:

$$
\sigma_{r 1}=0.675 \cdot k \cdot \frac{P_{1} \cdot L}{b \cdot h_{s p}^{2}} ; \quad \sigma_{r 2}=0.555 \cdot k \cdot \frac{P_{2} \cdot L}{b \cdot h_{s p}^{2}},
$$

where: $k$ is the scale factor; $P_{1}$ and $P_{2}$ are, respectively, the loads recorded at the mid-span deflection equal to $\delta_{1}=0.46 \mathrm{~mm}$ and $\delta_{2}=3.0 \mathrm{~mm}$ (Fig. 3a) or crack width equal to $w_{1}=0.5 \mathrm{~mm}$ and $w_{2}=3.5 \mathrm{~mm}$ (Fig. $3 \mathrm{~b}$ ); $L$ and $b$ are the span and the width of specimen, respectively; $h_{s p}$ is the depth of notched section.

\section{Experimental program}

An experimental program was conducted in order to investigate the effect of steel fibres on the response of members subjected to bending. Several beams were tested, containing $40 \mathrm{~kg} / \mathrm{m}^{3}$ and $80 \mathrm{~kg} / \mathrm{m}^{3}$ hooked-ended steel fibres (respectively equivalent to $0.5 \%$ and $1.0 \%$ of the total specimen volume). Fibres with a length $l_{f}$ of $50 \mathrm{~mm}$ and a diameter $d_{f}$ of $1 \mathrm{~mm}$, resulting in the aspect (length to diameter) ratio of 50 were used.

Standard $150 \times 150 \times 600 \mathrm{~mm}$ beams with the span of $500 \mathrm{~mm}$ were casted according to RILEM (2002a). Displacement controlled testing machine was used and (a)

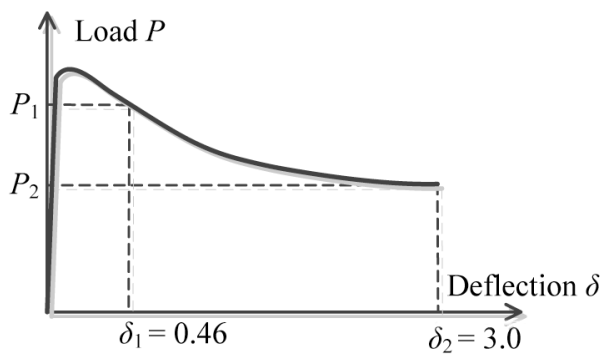

(b)

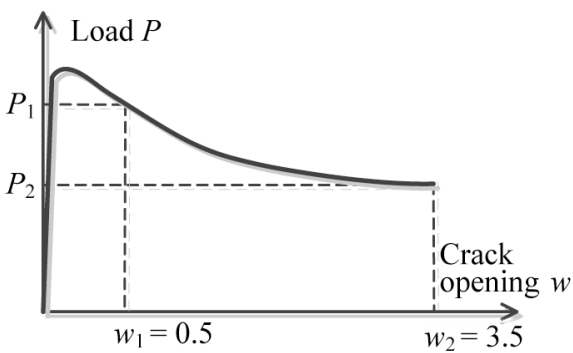

Fig. 3. Experimentally obtained load-deflection (a) and loadcrack width (b) relationships (RILEM 2002b)

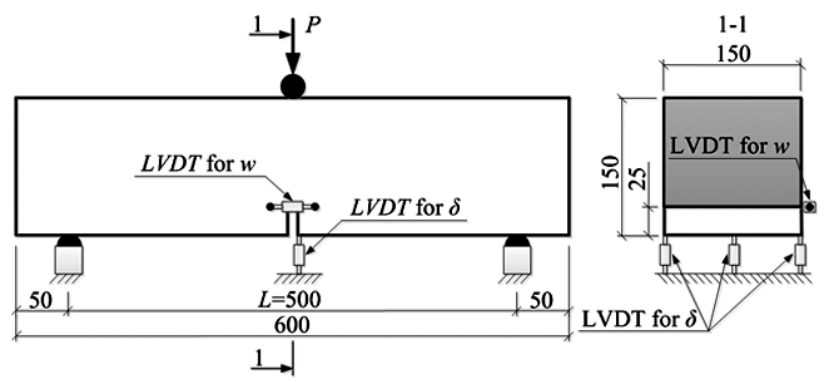

Fig. 4. The test set-up

beams were loaded with the rate of $0.2 \mathrm{~mm} / \mathrm{min}$. To localize cracking process, each beam was equipped with $25 \mathrm{~mm}$ notch at the mid-span. The mid-span deflections as well as crack opening width were measured within the test using linear variable displacement transducers (LVDTs). The test set-up is shown in Figure 4.

The compressive strength of concrete was measured at the age of 28 days on $150 \mathrm{~mm}$ cube specimens, resulting in average values of $43.1 \mathrm{MPa}$ and $44.8 \mathrm{MPa}$ for 0.5 and $1.0 \%$ steel fibre concrete mixes, respectively. From the test results of the individual beams in the test series, load-crack width curves have been constructed. Figures $5 \mathrm{a}$ and $5 \mathrm{~b}$ show the load-crack width curves for 0.5 and $1.0 \%$ of fibre content, respectively. It can be observed that for most of the specimens the cracking resistance increases with increased volume of fibres. However, the variability in the obtained diagrams is significant. Such variety of results was mainly influenced by the orientation and number of fibres acting at the crack section.

\section{Proposed inverse analysis technique}

In the current study, an inverse procedure has been proposed to perform constitutive analysis of SFRC in tension. The technique employs experimental data from standard 3-point bending tests and uses simple equilibrium of axial forces and bending moments to find unknown values of the parameters defining the residual stresses in SFRC. 
(a)

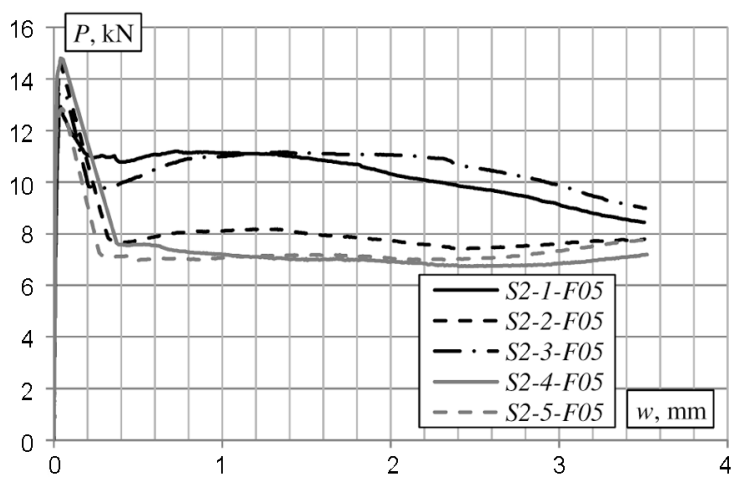

(b)

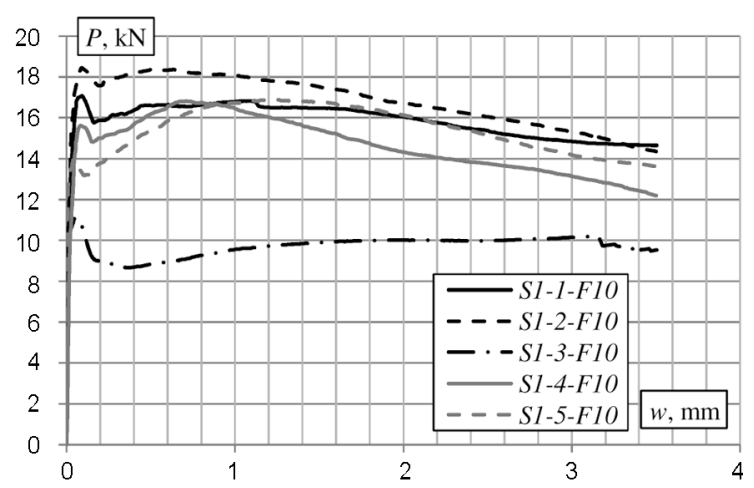

Fig. 5. Experimentally obtained load-crack opening width relationships for the test specimens with $0.5 \%$ (a) and $1.0 \%$ (b) fibre volumes

It is assumed that at the crack, the tensile strain approaches infinity, whereas the stress-strain relation before cracking defines the strain at a distance besides the crack. To determine tensile strain of concrete at a certain loading step, a length, further called influence length, is considered. For the beam, shown in Figure 6, the influence length over which the stresses are distributed due to the opening crack is taken equal to two times the height of the tensile zone (Dupont 2003).

The unknown position of the neutral axis is obtained from expression of residual stresses by simultaneously solving equilibrium equations of axial forces and bending moments:

$$
\begin{gathered}
\sigma_{r, n}=0.5 E\left[\varepsilon_{n}^{2}(\bar{h}-1)-\varepsilon_{c r}^{2}\right]-\sum_{i=2}^{n} \sigma_{r, i-1}\left(\varepsilon_{i-1}-\varepsilon_{i-2}\right)= \\
\frac{\frac{P_{n} L \varepsilon_{n}^{2}}{2 b y_{n}^{2}}-\frac{2 E}{3}\left[\varepsilon_{n}^{3}(\bar{h}-1)+\varepsilon_{c r}^{3}\right]-\sum_{i=2}^{n} \sigma_{r, i-1}\left(\varepsilon_{i-1}^{2}-\varepsilon_{i-2}^{2}\right)}{\varepsilon_{n-1}+\varepsilon_{n}} .
\end{gathered}
$$

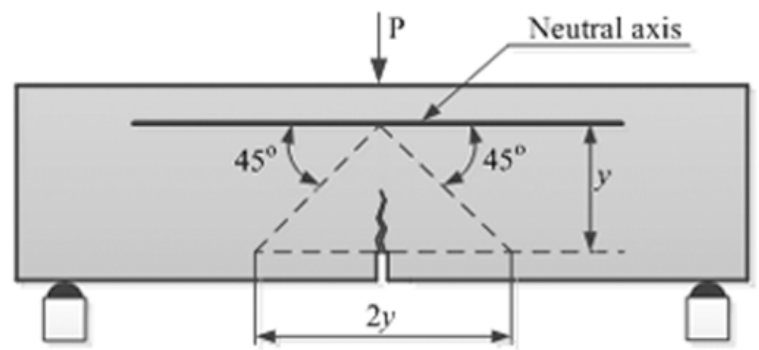

Fig. 6. Definition of the influence length for a beam (a)
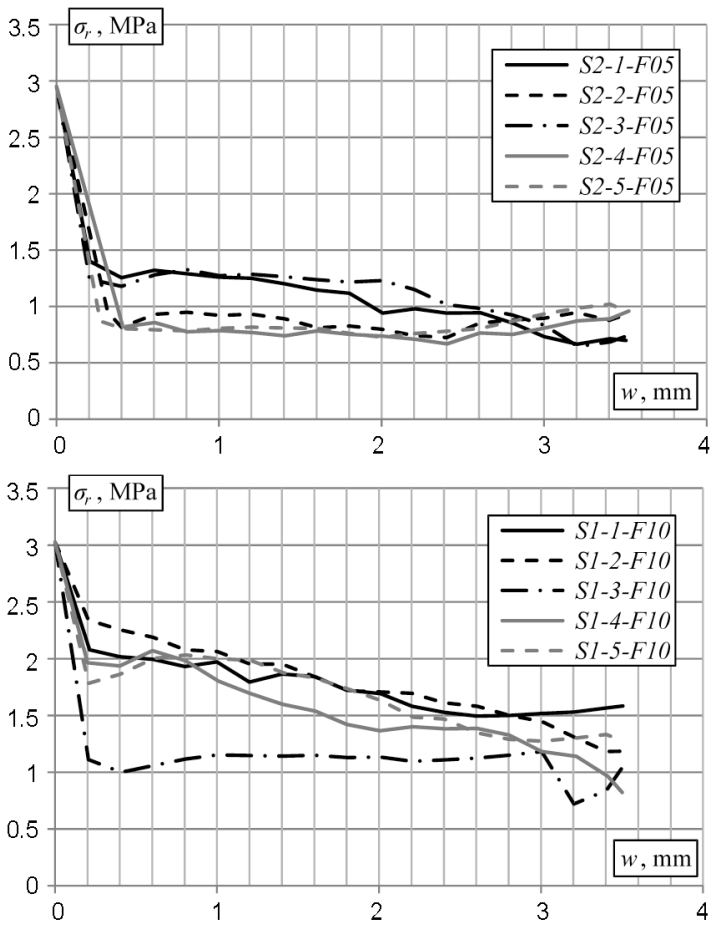

Fig. 7. Determined residual stress-crack width relationships for the test specimens with $0.5 \%$ (a) and $1.0 \%$ (b) fibre volumes

Residual stresses and, therefore, crack width can be found from equilibrium of axial forces:

$$
\begin{gathered}
\quad 0.5 E\left[(\bar{h}-1)^{2}-\varepsilon_{c r}^{2} y_{n}^{2} / \varepsilon_{n}^{2}\right]-\sum_{i=1}^{n} \sigma_{r, i}\left(\varepsilon_{i}-\varepsilon_{i-1}\right)=0 ; \\
\bar{h}=h_{s p} / y_{n}, \quad \varepsilon_{c r}=f_{c t} / E, \quad \varepsilon_{n}=w_{n} /\left(2 y_{n}\right), \quad \varepsilon_{0}=\varepsilon_{c r} .
\end{gathered}
$$

In Eqns (3) and (4), $n$ is the loading step under consideration; $\sigma_{r, n}$ is the residual stresses, $\varepsilon_{n}$ is the deformation of element, $w_{n}$ is the crack width, $y_{n}$ is the position of neutral axis, and $P_{n}$ is the load at $n$-th step; $E$ and $f_{c t}$ are the deformation modulus and tensile strength of SFRC; $h_{s p}$ is the depth of the notched section; $L$ and $b$ are the span and the width of specimen, respectively.

It should be mentioned that with increase in loading, the position of the neutral axis changes; thus, it should be identified for every loading step, considered in the analysis. Obtained residual stress-crack width relationships for the beams with 0.5 and $1.0 \%$ of fibres are given in Figures $7 \mathrm{a}$ and $7 \mathrm{~b}$, respectively.

\section{Numerical modelling}

\subsection{Standard beams}

This section considers standard SFRC beams tested in the current study (Section 2). Adequacy of the residual stresscrack width $\left(\sigma_{f r}-w\right)$ relationships obtained by Naaman (2003) and RILEM (2002a) methods and derived by the proposed technique was verified using nonlinear finite element (FE) program ATENA. Figure 8 presents the test beam modelled employing the derived $\sigma_{r}-w$ diagrams as constitutive models for SFRC in tension. Simulated loadcrack width $(P-w)$ relations for the beams with 0.5 and 
$1.0 \%$ of fibres are given in Figures 9 and 10, respectively. As it can be seen, the horizontal parts of $P-w$ curves, representing the residual loads, has an error up to 10,25 , and $65 \%$ for the proposed technique and for the RILEM and Naaman methods, respectively.

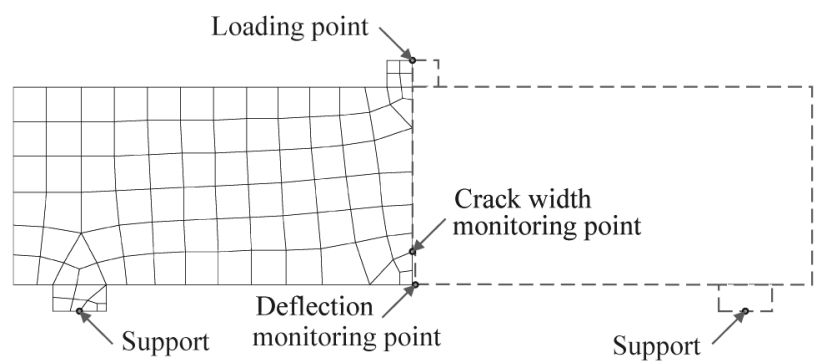

Fig. 8. Model of experimental beam using FE software ATENA

\subsection{Full-scale beams}

This section considers full-scale SFRC beams with steel bar reinforcement, tested by the authors. Two beams were selected from the test program reported by Gribniak et al. (2012) with similar concrete mixture and fibre volumes as the standard specimens (Section 2). The specimens were reinforced with three $10 \mathrm{~mm}$ bars, resulting in tensile reinforcement ratio of $0.3 \%$. Main parameters of the beams are listed in Table 1, where $V_{f}$ is the volume content of fibres in the concrete mixture; $f_{c}^{\prime}$ is the $\varnothing 150 \times 300 \mathrm{~mm}$ cylinder strength; $E_{s}$ is the elastic modulus of the bar reinforcement.

Investigation of $\mathrm{FE}$ mesh dependence on modelling results of flexural members has shown that models of reinforced concrete beams having 6-8 finite elements per height demonstrate sufficient accuracy (Gribniak et al. 2010). In the current study, six elements per height were taken for FE modelling (Fig. 11). Due to symmetry conditions, only half of the beam was modelled. Isoparametric quadrilateral $\mathrm{FE}$ with 8 degrees of freedom and four integration points were used. Bar reinforcement was modelled by truss elements. The tension-stiffening effect was included in the FE model using principles of fracture mechanics (Gribniak et al. 2013a).
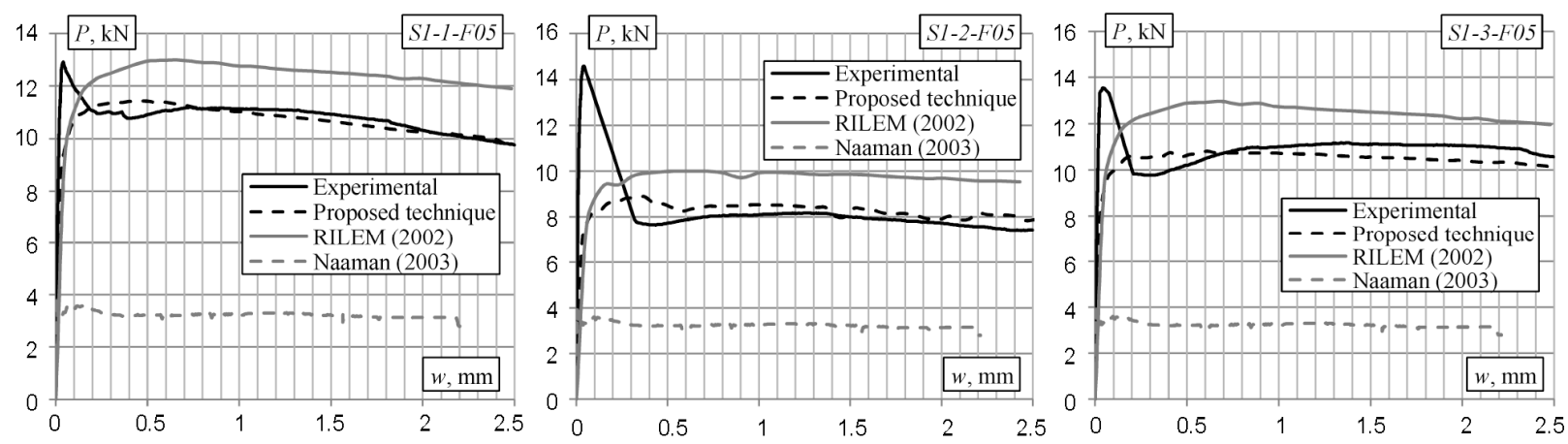

Fig. 9. Comparison of experimental and calculated P-w curves for the experimental beams with $0.5 \%$ volume of fibres
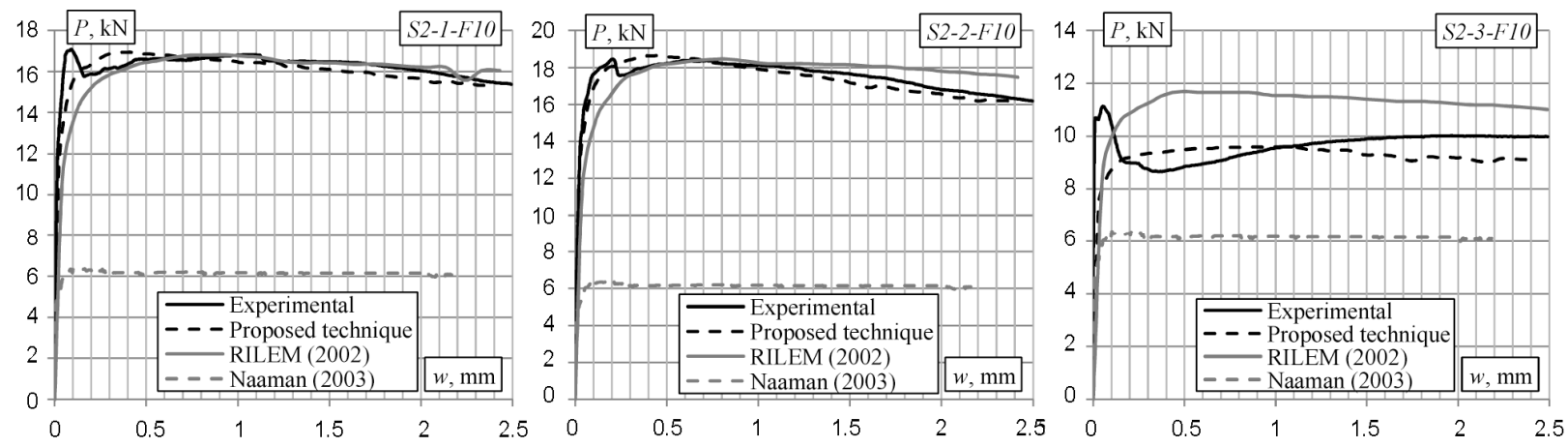

Fig. 10. Comparison of experimental and calculated $\mathrm{P}-\mathrm{w}$ curves for the experimental beams with $1.0 \%$ volume of fibres

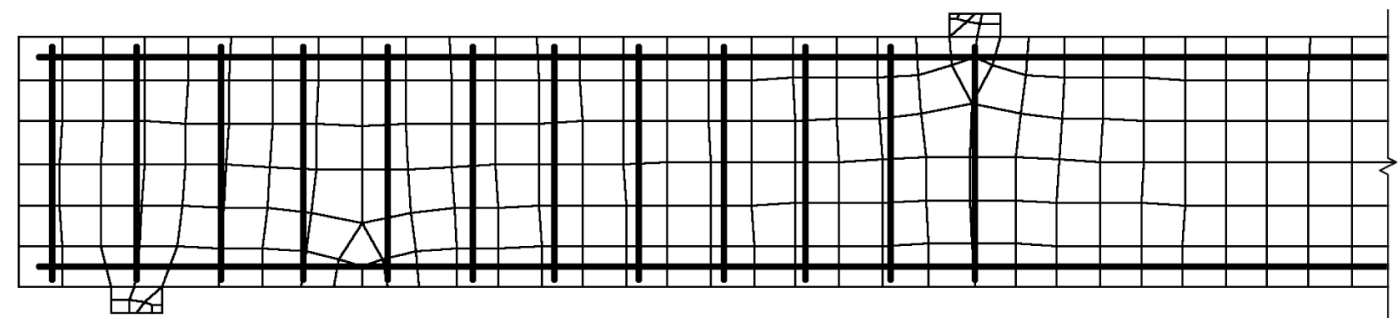

Fig. 11. Finite element meshing of a beam 
Table 1. Geometric and material parameters of the full-scale beams

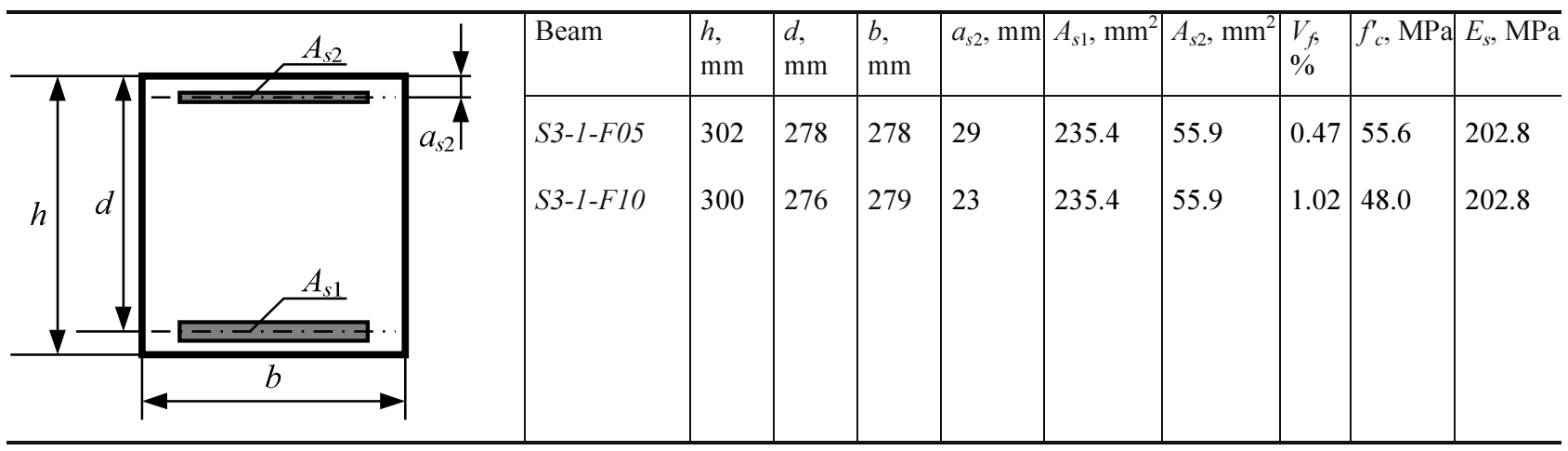
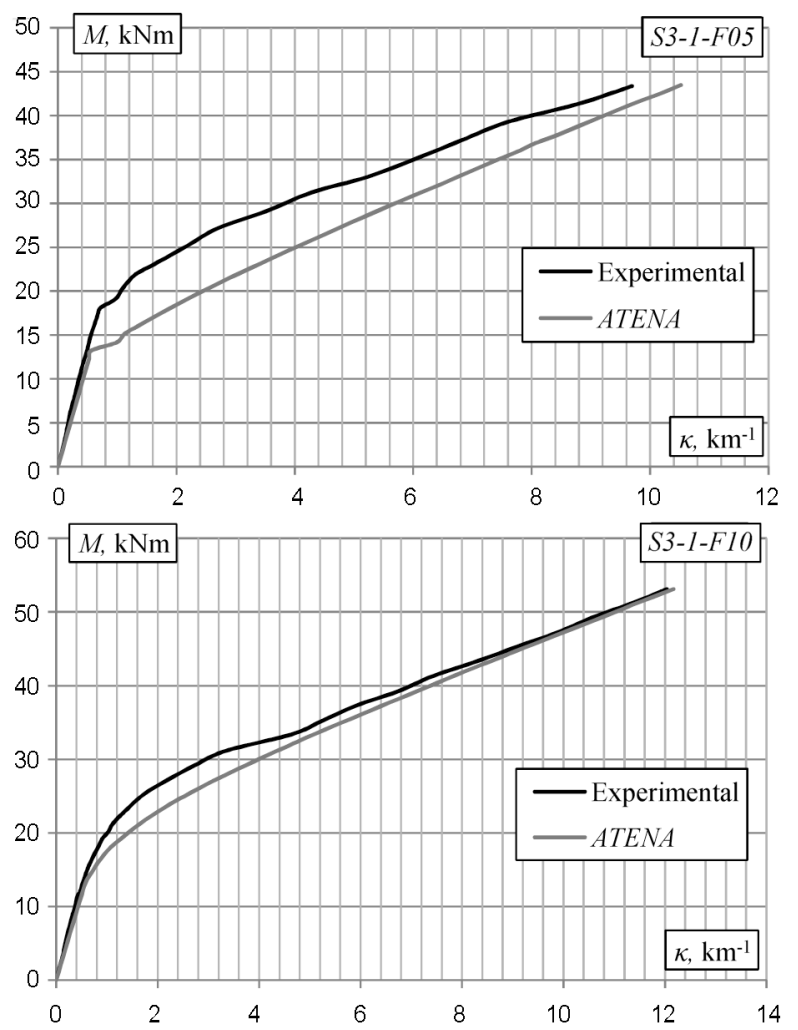

Fig. 12. Deformation analysis results on full-scale beams

Modelling results are presented in Figure 12. It can be observed that curvature is obviously overestimated for the beam with $0.5 \%$ of fibres. This is mainly due to the non-homogeneous distribution of the fibres in the standard concrete specimens, used for the constitutive modelling of SFRC. The employed material law $\left(\sigma_{f r}-w\right.$ relationship) was derived for a single section, which not necessarily contains sufficient number of fibres and may not represent the average deformation behaviour of fullscale beam. Furthermore, the tension-stiffening effect was included into FE model in "default" manner, but not assessed from the standard SFRC beams (without bar reinforcement) that may become another source of overestimated deformations of the full-scale beam. Increasing volume of fibres makes concrete more homogeneous. Increased residual strength of SFRC relatively reduces the effect of tension-stiffening (Fig. 1). Therefore, the assumed material law more adequately represents defor- mation behaviour of full-scale beam with $1.0 \%$ of fibres than for $0.5 \%$ (Fig. 12).

\section{Conclusions}

The paper deals with experimental and theoretical investigation of the post-cracking behaviour of steel fibre reinforced concrete (SFRC). Ten standard beams equipped with notch and containing fibre contents of 0.5 and $1.0 \%$ by volume were tested under a three-point bending scheme. For the determination of the residual strength of SFRC in tension, a simple method based on the general principles of material mechanics was proposed. The main advantage of the proposed technique (in comparison with the methods provided by the RILEM or Naaman) is its capability to calculate residual stresses and, thus, crack width at any loading step.

To verify the obtained residual stress-crack opening relation a nonlinear finite element analysis program ATENA was utilized. The proposed constitutive analysis technique was found to be accurate determining the residual stresses in SFRC. The numerical simulation of full scale SFRC beams with steel bars has revealed importance of the sufficient amount of fibres in concrete and, therefore, residual strength on deformation prediction results: with increased volume of fibres (from 40 to $80 \mathrm{~kg} / \mathrm{m}^{3}$ ) the residual strength becomes the governing criterion for the finite element modelling.

\section{Acknowledgements}

The authors gratefully acknowledge the financial support provided by the Research Council of Lithuania (Research Project MIP-083/2012). Viktor Gribniak and Aleksandr $\mathrm{K}$. Arnautov wish to acknowledge the support by the European Social Fund (Research Project No. 2013/0019/1DP/1.1.1.2.0/13/APIA/VIAA/062).

\section{References}

Campione, G. 2008. Simplified flexural response of steel fiber reinforced concrete beams, ASCE Journal of Materials in Civil Engineering 20(4): 283-293.

http://dx.doi.org/10.1061/(ASCE)0899-1561(2008)20:4(283)

Chao, S. H.; Naaman, A. E.; Parra-Montesinos, G. J. 2009. Bond behavior of reinforcing bars in tensile strainhardening fiber-reinforced cement composites, ACI Structural Journal 106(6): 897-906. 
CEN (European Committee for Standardization). 2005. Test method for metallic fibered concrete - measuring the flexural tensile strength, EN 14651. Brussels: CEN. 112 p.

CNR 2007. Guide for the design and construction of fiberreinforced concrete structures, CNR-DT 204/2006. Roma: National Research Council, Advisory Committee on Technical Recommendations for Construction. $57 \mathrm{p}$.

DAfStb. (German Committee for Structural Concrete) 2010. Technical Rule on Steel Fibre Concrete. Berlin: DAfStb. 47 p. (in German).

DBV (German Concrete and Construction Technology Association). 2001. DBV-steel fiber reinforced concrete. Berlin: DBV. 79 p.

Di Prisco, M.; Plizzari, G.; Vandewalle, L. 2009. Fibre reinforced concrete: new design perspectives, Materials and Structures 42(9): 1261-1281.

http://dx.doi.org/10.1617/s11527-009-9529-4

Dupont, D. 2003. Modeling and experimental validation of the constitutive law $(\sigma-\varepsilon)$ and cracking behavior of steel fibre reinforced concrete: PhD Thesis [online], [cited 15 December 2013]. Leuven: Catholic University of Leuven. 256 p. Available from Internet:

http://bwk.kuleuven.be/mat/publications/phdthesis/2003dupont-ph-d.pdf

Fuggini, C.; Chatzi, E.; Zangani, D. 2013. Combining genetic algorithms with a meso-scale approach for system identification of a smart polymeric textile, Computer-Aided $C i$ vil and Infrastructure Engineering 28(3): 227-245. http://dx.doi.org/10.1111/j.1467-8667.2012.00789.x

Ganesan, N.; Indira, P. V.; Sabeena, M. V. 2014. Bond stress slip response of bars embedded in hybrid fibre reinforced high performance concrete, Construction and Building Materials 50: 108115. http://dx.doi.org/10.1016/j.conbuildmat.2013.09.032

Gribniak, V.; Kaklauskas, G.; Idnurm, S.; Bacinskas, D. 2010. Finite element mesh size effect on deformation predictions of reinforced concrete bridge girder, The Baltic Journal of Road and Bridge Engineering 5(1): 19-27. http://dx.doi.org/10.3846/bjrbe.2010.03

Gribniak, V.; Kaklauskas, G.; Kwan, A. K. H.; Bačinskas, D.; Ulbinas, D. 2012. Deriving stress-strain relationships for steel fibre concrete in tension from tests of beams with ordinary reinforcement, Engineering Structures 42: 387395. http://dx.doi.org/10.1016/j.engstruct.2012.04.032

Gribniak, V.; Cervenka, V.; Kaklauskas, G. 2013a. Deflection prediction of reinforced concrete beams by design codes and computer simulation, Engineering Structures 56: 21752186. http://dx.doi.org/10.1016/j.engstruct.2013.08.045

Gribniak, V.; Kaklauskas, G.; Kliukas, R.; Jakubovskis, R. 2013b. Shrinkage effect on short-term deformation behavior of reinforced concrete - when it should not be neglected, Materials and Design 51: 1060-1070. http://dx.doi.org/10.1016/j.matdes.2013.05.028
Gribniak, V.; Kaklauskas, G.; Torres, L.; Daniunas, A.; Timinskas, E.; Gudonis, E. 2013c. Comparative analysis of deformations and tension-stiffening in concrete beams reinforced with GFRP or steel bars and fibers, Composites Part B: Engineering 50: 158170. http://dx.doi.org/10.1016/j.compositesb.2013.02.003

Holschemacher, K.; Mueller, T.; Ribakov, Y. 2010. Effect of steel fibres on mechanical properties of high-strength concrete, Materials and Design 31(5): 2604-2615. http://dx.doi.org/10.1016/j.matdes.2009.11.025

Kaklauskas, G.; Gribniak, V.; Girdzius, R. 2011. Average stress-average strain tension-stiffening relationships based on provisions of design codes, Journal of Zhejiang University SCIENCE A 12(10): 731-736. http://dx.doi.org/10.1631/jzus.A1100029

Lee, S. L.; Cho, J. Y.; Vecchio, F. J. 2013. Tension-stiffening model for steel fiber-reinforced concrete containing conventional reinforcement, ACI Structural Journal 110(4): 639-648.

Lofgren, I.; Stang, H.; Olesen, J. F. 2005. Fracture properties of FRC determined through inverse analysis of wedge splitting and three-point bending tests, Journal of Advanced Concrete Techno$\operatorname{logy} 3(3)$ : 423-434. http://dx.doi.org/10.3151/jact.3.423

Naaman, A. E. 2003. Engineered steel fibers with optimal properties for reinforcement of cement composites, Journal of Advanced Concrete Technology 1(3): 241-252. http://dx.doi.org/10.3151/jact.1.241

Pujadas, P.; Blancoa, A.; Cavalaroa, S.; De la Fuentea, A.; Aguado, A. 2013. New analytical model to generalize the Barcelona test using axial displacement, Journal of Civil Engineering and Management 19(2): 259-271. http://dx.doi.org/10.3846/13923730.2012.756425

RILEM TC 162-TDF 2001. Uniaxial tension test for steel fibre reinforced concrete, Materials and Structures 34(1): 3-6. http://dx.doi.org/10.1617/13628

RILEM TC 162-TDF 2002a. Design of steel fibre reinforced concrete using the $\sigma-\mathrm{W}$ method: principles and applications, Materials and Structures 35(5): 262-278. http://dx.doi.org/10.1617/13837

RILEM TC 162-TDF 2002b. Bending test. Final recommendation, Materials and Structures 35(9): 579-582. http://dx.doi.org/10.1007/BF02483127

RILEM TC 162-TDF 2003. $\sigma-\varepsilon$ design method, Materials and Structures 36(8): 560-567. http://dx.doi.org/10.1617/14007

Slowik, V.; Villmann, B.; Bretschneider, N. 2006. Computational aspects of inverse analyses for determining softening curves of concrete, Computer Methods in Applied Mechanics and Engineering 195(52): 7223-7236. http://dx.doi.org/10.1016/j.cma.2005.04.021

Adas MESKENAS. PhD student and an Assistant Professor in the Department of Bridges and Special Structures at VGTU. His research interests include various topics on fibre reinforced concrete (FRC), particularly constitutive modelling and numerical simulation of steel fibre reinforced concrete (SFRC) structures.

Viktor GRIBNIAK. Senior Researcher at the Civil Engineering Research Centre at VGTU, Lithuania. PhD degree obtained from VGTU. He is a member of the fib Task Group 4.1 "Serviceability Models". In 2013, he received the ASCE Moisseiff Award for a paper contributing to structural design. His research interests include serviceability analysis and numerical modelling of reinforced concrete (RC) structures, innovative types of reinforcement for concrete. 
Gintaris KAKLAUSKAS. Professor and Head of the Department of Bridges and Special Structures at VGTU, Lithuania. $\mathrm{PhD}$ and Dr Sc degrees received from VGTU. He is an Academician at the Lithuanian Academy of Science and a member of the fib Task Group 4.1 "Serviceability Models", recipient of Fulbright and Marie Curie (senior research category) fellowships. In 2013, he received the ASCE Moisseiff Award for a paper contributing to structural design. Research interests include various topics on reinforced concrete, particularly constitutive modelling, and numerical simulation of reinforced concrete structures.

Aleksandr K. ARNAUTOV. Senior Researcher at the Institute of Polymer Mechanics (IMP) of the University of Latvia, Riga, Latvia. PhD degree obtained from IMP. His research interests include theoretical and experimental studies of deformation and fracture of materials, mechanics of composite structure, and test methods for determining mechanical properties composite.

Arvydas RIMKUS. PhD student in the Department of Bridges and Special Structures and an Assistant Professor in the Department of Engineering Graphics at VGTU. His research interests focus on the optimal section of the structural composite materials and combinations of their mechanical properties with specific emphasis on the effective reinforcement schemes, developed considering structural and technological aspects. 